\section{Dental erosion}

\section{Bitterness-induced bruxism}

Sir, each year in late December the same patient presents with the same bruxisminduced symptoms. Over the past few years tooth wear has become increasingly evident on the cusps of the occlusal surface on the patient's posterior teeth and he reports suffering from tired jaw muscles which has even resulted in sleep disruption.

I struggled to treat the patient as he refused follow-up appointments, stating they were too expensive. I have also repeatedly urged the patient to use fluoride toothpaste, but he refuses, claiming that this is also overpriced. I have told the man to come in and get to know me better - I firmly believe in developing friendly dentist-patient relationships - but it did not seem to be in his nature. Personally, after taking his history and learning a little about him, I have come to the conclusion that the patient's bruxism is a symptom of his bitterness. He dislikes everyone, detests charity and the mere mention of Christmas considerably worsens his mood and causes him to grind his teeth. This year I went to great lengths

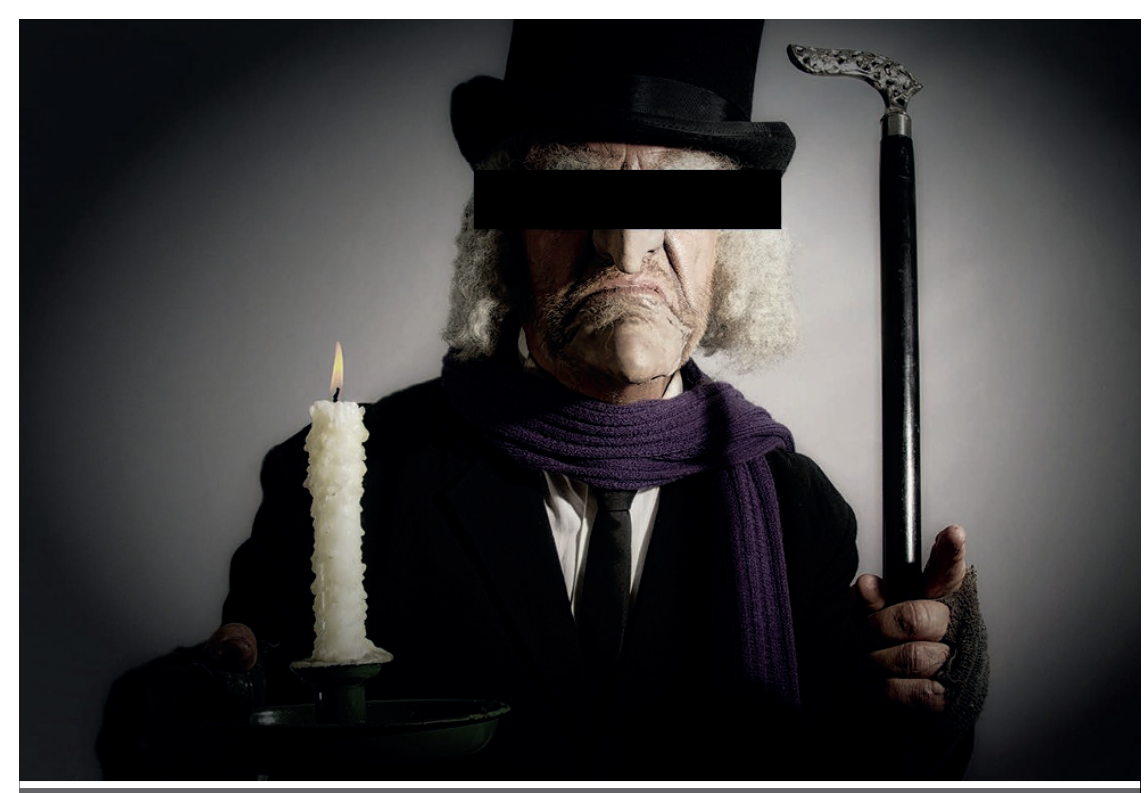

Fig. 1 The bitter bruxism patient

to help: showing him both past and a present radiographs to highlight the deterioration of his teeth. However, I saw no improvement in his attitude until I showed him another patient's radiograph demonstrating how his teeth will suffer in future years yet to come if he continues to decline treatment.
I was shocked at the immediacy of his change. He booked a follow-up appointment there and then, and tipped me on his way out of the practice.

J. Marley, by email DOl: 10.1038/sj.bdj.???

\section{Cracking down on a Christmas classic}

Sir, I'm afraid I write to you at this most merry time of year to draw your attention to a much more sobering issue. A great deal has been made of the damaging and erosive nature of sour and novelty sweets in your journal recently. ${ }^{1}$ However, you make little reference to something which is widely discussed in my December waiting rooms and seems to me to be an annual plaque-inducing confectionery craze: the 'Nutcracker Sweet'.

Whilst I've yet to encounter these 'delights' in person, I'm told they were first imported from Russia by a man called Tchaikovsky some 200 years ago and apparently remain popular at this festive time: the sweet seems to be associated with a twinkling (and decidedly lengthy!) jingle and dancing fairies, and is plugged relentlessly in the media. Now they have seemingly become one of the nation's firm festive favourites during the Christmas period. Despite this, however, there has been a startling lack of research or even willingness to address what I'm convinced is responsible for the large rise in dental caries treatments required in children in the months following Christmas.

Its advocates cite the sweet's heritage and role in our Christmas culture as genuine reasons to continue promoting this decay-inducing detritus. I have even heard murmurings of a new product line, something that will be apparently be marketed as 'Sugar Plum Fairies' in the coming months. Bah humbug I say! Dentistry has a collective responsibility to raise awareness and limit the damage to our patients at what, I'm sure you'll agree, is a particularly stressful time of year for the profession.

I am confident that by bringing this matter to your attention, we can both inform the general public of the hidden dangers posed by regular consumption of this 'Nutcracker Sweet', and secondly, be able to implement some effective form of control and regulation surrounding yet another imported festive blight.

\section{S. C. Rooge, by email}

1. Aljawad A, Morgan M Z, Fairchild R and Rees J S. Investigation of the erosive potential of sour novelty sweets. Br Dent J 2017; 222: 613-620.

DOI: 10.1038/sj.bdj.2017.1095

\section{Safeguarding}

\section{Graphic Christmas cards}

Sir, we write to you at this festive time to remind your readers about some concerns in relation to the use of social media.

As you will be aware, the GDC issued guidance on social media usage ${ }^{1}$ specifically noting that registrants have a responsibility when they are online to maintain an image that does not bring the profession into disrepute.

Patients have brought our attention to a number of dental practice websites (and 'pages' on social media) that have hosted Christmas card design competitions for their child patients whose content we feel may contravene this guidance. We have been advised about graphic images of stockings, filled and unfilled and depictions of halfdrunk glasses of sherry. We believe these are safeguarding issues for this age group.

We have been alerted also to a drawing by a nine-year-old child, gender not specified (possibly fluid), of his or her Mummy kissing Santa Claus. One of them, we are unsure 